\title{
Estimación de los resultados de la evaluación de carácter diagnostica formativa (ECDF) 2016 en el municipio de Soacha-Cundinamarca
}

\section{Estimation of the results of the evaluation of the diagnostic formative character (ECDF) 2016 in the municipality of Soacha-Cundinamarca}

Jorge Enrique Díaz Pinzón

Consultor Independiente, Colombia

Autor para correspondencia: jorgediaz333@gmail.com

Fecha de recepción: 11 de Mayo de 2017 - Fecha de aceptación: 15 de Septiembre de 2017

\section{Resumen}

Este trabajo de investigación tuvo por objetivo comparar si hay diferencias entre el sexo del docente y el resultado obtenido en la prueba de ECDF, además de comparar los promedios obtenidos por los docentes en las diferentes instituciones educativas del municipio de SoachaCundinamarca. Se realizó una comparación múltiple entre medias independientes, a partir del análisis estadístico de los datos aplicando la prueba T-Student, se pudo observar que hay evidencia para rechazar la hipótesis alterna, por tanto las medias son iguales. La calificación promedio del sexo femenino fue de 77,4247 y del sexo masculino fue de promedio fue 77,04685. La institución educativa con menor promedio fue Compartir con 59,8520 y la de mejor promedio fue la institución educativa Manuela Beltrán con un promedio de 84,0513.

Palabras claves: evaluación del docente; evaluación comparativa; evaluación formativa

\begin{abstract}
This research aimed to compare if there are differences between the sex of the teacher and the result obtained in the ECDF test, in addition to comparing the averages obtained by the teachers in the different educational institutions of the municipality of Soacha-Cundinamarca. A multiple comparison between independent means was made, based on the statistical analysis of the data using the T-Student test, it was observed that there is evidence to reject the alternate hypothesis, so the means are the same. The average female grade was 77.4247 and the average male was 77.04685. The educational institution with the lowest average was Sharing with 59,8520 and the one with the best average was the educational institution Manuela Beltrán with an average of 84,0513 .
\end{abstract}

Key words: teacher evaluation; comparative evaluation; formative evaluation 


\section{Introducción}

La evaluación de carácter diagnostico formativo involucra un proceso de reflexión e indagación, encaminado a identificar en su conjunto las situaciones, los aciertos y las necesidades en que se realiza el trabajo de los docentes, directivos docentes, directivos sindicales, docentes tutores y orientadores, esto con el objetivo de incidir de forma positiva en la transformación de su práctica educativa pedagógica, directiva y/o sindical, su mejora continua, sus situaciones y beneficiar los avances en los conocimientos pedagógicos y educativos en la escuela. (MEN, 2015)

Esto debido al Decreto No 1757 de 2015,

Por el cual se adiciona el Decreto 1075 de 2015 y se reglamenta parcial y transitoriamente el Decreto Ley 1278 de 2002, en materia de evaluación para ascenso de grado y reubicación de nivel salarial que se aplicará a los educadores que participaron en alguna de las evaluaciones de competencias desarrolladas entre los años 2010 y 2014 Y no lograron el ascenso o la reubicación salarial en cualquiera de los grados del Escalafón Docente (MEN, 2015)

En consonancia con lo anterior, esta evaluación tendrá un enfoque cualitativo, que implicará consideraciones acerca del contexto en el cual se desempeña el educador, se centrará en la valoración del quehacer del educador en el aula o en los diferentes contextos en los se ponga en evidencia su capacidad de interactuar con los actores de la comunidad educativa, en el marco del Proyecto Educativo Institucional. (MEN, 2015)

Como objetivo de esta investigación se planteó comparar si hay diferencias entre el sexo del docente y el resultado obtenido en la prueba de ECDF, además de comparar los promedios obtenidos por los docentes en las diferentes instituciones educativas del municipio de SoachaCundinamarca. La validación de los datos estadísticos se realizó a través del paquete SPSS v.20.

\section{Población}

La población según (Balestrini,2006,p.126), se define como "cualquier conjunto de elementos de la que se quiere conocer o investigar alguna de sus características". Esta investigación se centró en docentes del municipio de Soacha-Cundinamarca, con 199 mujeres y 78 hombres, para un total de 277 docentes, que presentaron la ECDF en el año 2016.

\section{Resultados}

En la Tabla 1, se observan el número de docentes por sexo y su media correspondiente.

\begin{tabular}{|l|l|c|c|c|c|}
\hline \multicolumn{6}{|c|}{ Tabla 1. Estadísticos de grupo } \\
\hline \multirow{3}{*}{ Calificación } & Sexo & N & Media & Desviación típ. & Error típ. de la media \\
\cline { 2 - 7 } & Femenino & 199 & 77,4247 & 19,98012 & 1,41635 \\
\cline { 2 - 7 } & Masculino & 78 & 77,0468 & 20,29676 & 2,29816 \\
\hline
\end{tabular}

\section{Igualdad de varianza}


Prueba de Levene

P- valor $=>\alpha$ Aceptar Ho $=$ Las varianzas son iguales.

P- Valor $<\alpha$ Aceptar $\mathrm{Ha}=$ Existe diferencia significativa entre las varianzas.

En la tabla 2 se aprecia que el P-Valor $=0,962$ es mayor $\alpha=0.05$, Se rechaza Ha y se acepta Ho, es decir que no existe diferencia significativa entre las varianzas.

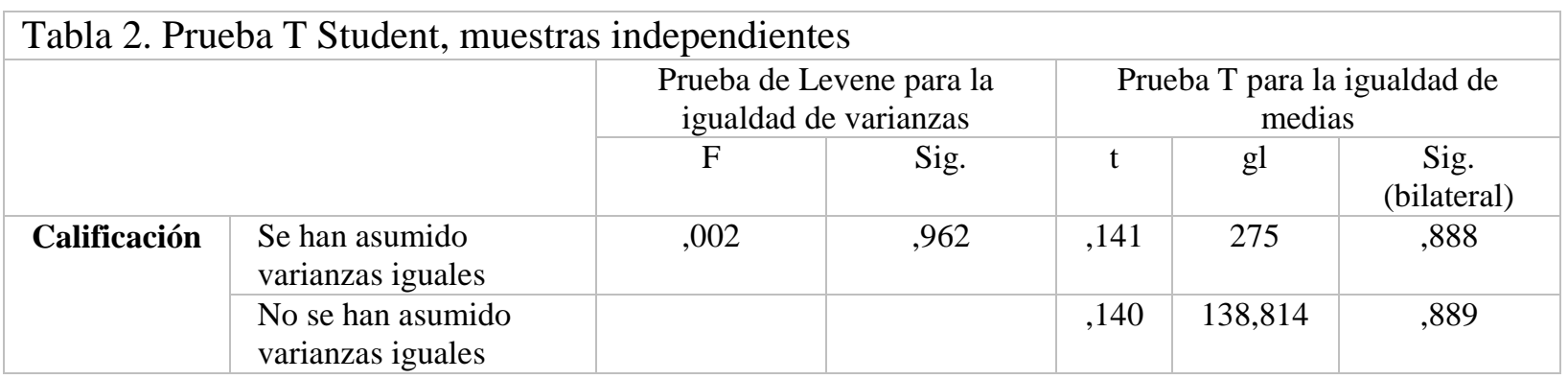

Concluimos que no existe una diferencia significativa entre la media de calificaciones de los docentes de sexo femenino y masculino.

En la figura 1, se observan los docentes que participaron en la ECDF por institución educativa, las instituciones que presentaron mayor participación de docentes fueron: Nuevo Compartir, León XIII, El Bosque, Las Villas y General Santander. Las instituciones que presentaron menor participación de docentes fueron: Eugenio Díaz Castro, Cazucá, Luis Carlos Galán, Gabriel García Márquez.

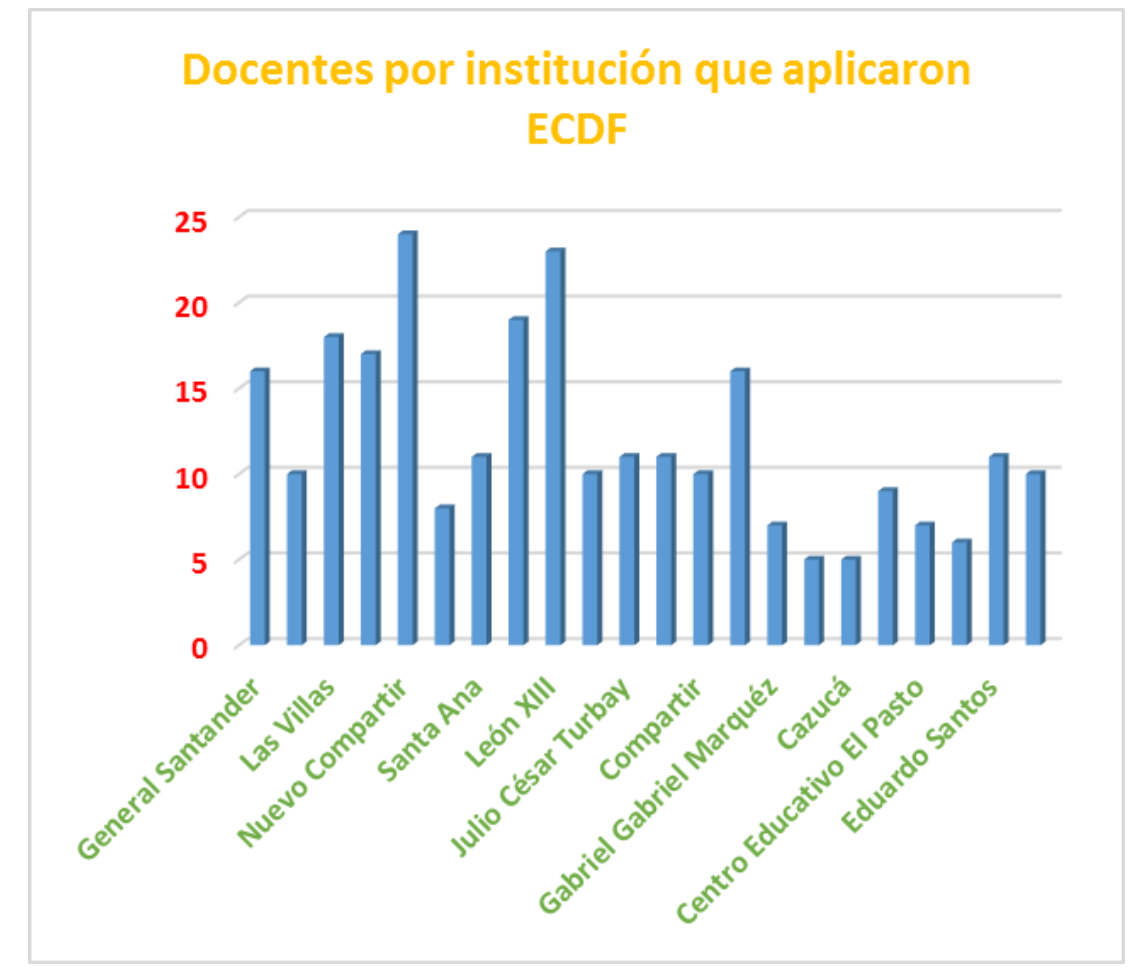


Figura 1. Docentes por institución que aplicaron la ECDF Fuente: Autor

En la figura 2, se observan los promedios obtenidos por cada una de las instituciones educativas en forma ascendente, que van desde 59,8520 de la institución educativa Compartir hasta 84,0513 de la institución educativa Manuela Beltrán.

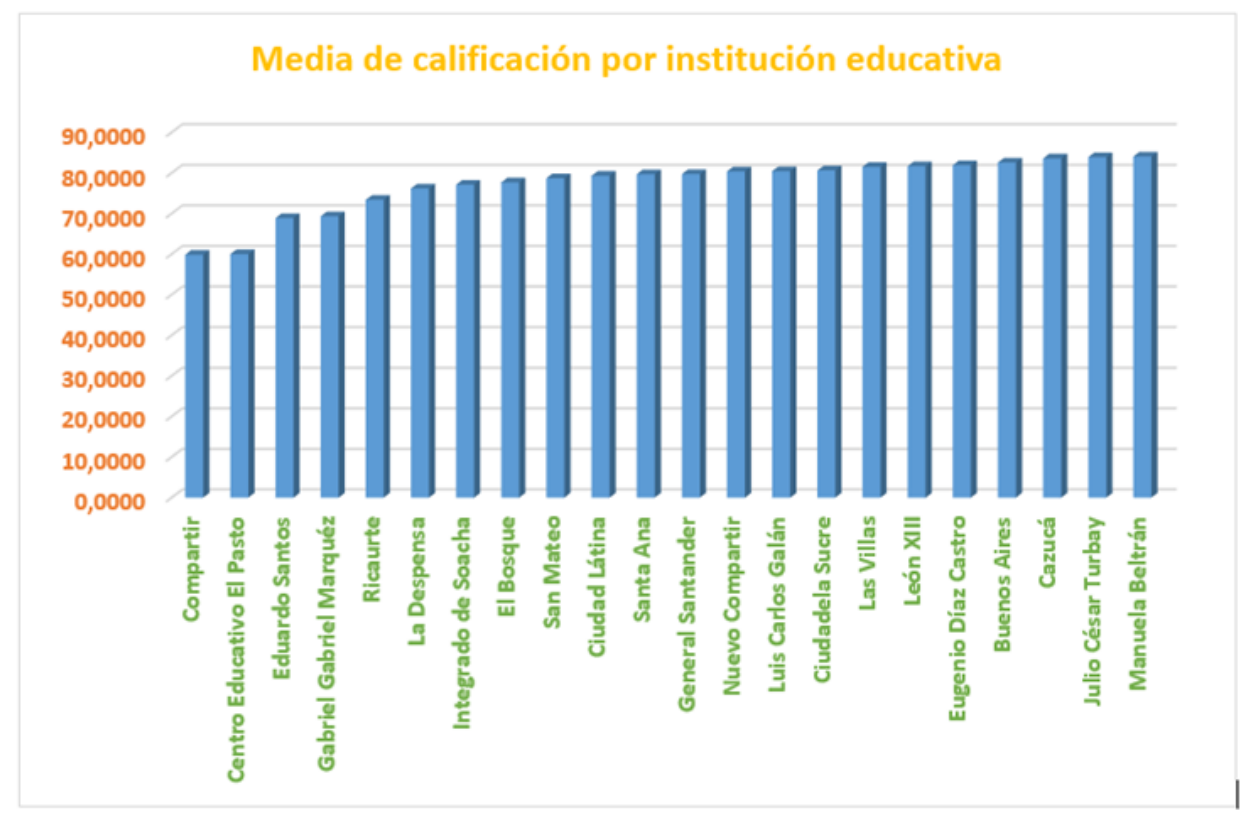

Figura 2. Media de calificación en cada nivel de complejidad del simulador Phet

Fuente: Autor

\begin{tabular}{|c|c|c|c|c|c|}
\hline & & Frecuencia & Porcentaje & Porcentaje válido & Porcentaje acumulado \\
\hline \multirow[t]{3}{*}{ Válidos } & Aprobado & 186 & 67,1 & 67,1 & 67,1 \\
\hline & No aprobado & 91 & 32,9 & 32,9 & 100,0 \\
\hline & Total & 277 & 100,0 & 100,0 & \\
\hline
\end{tabular}




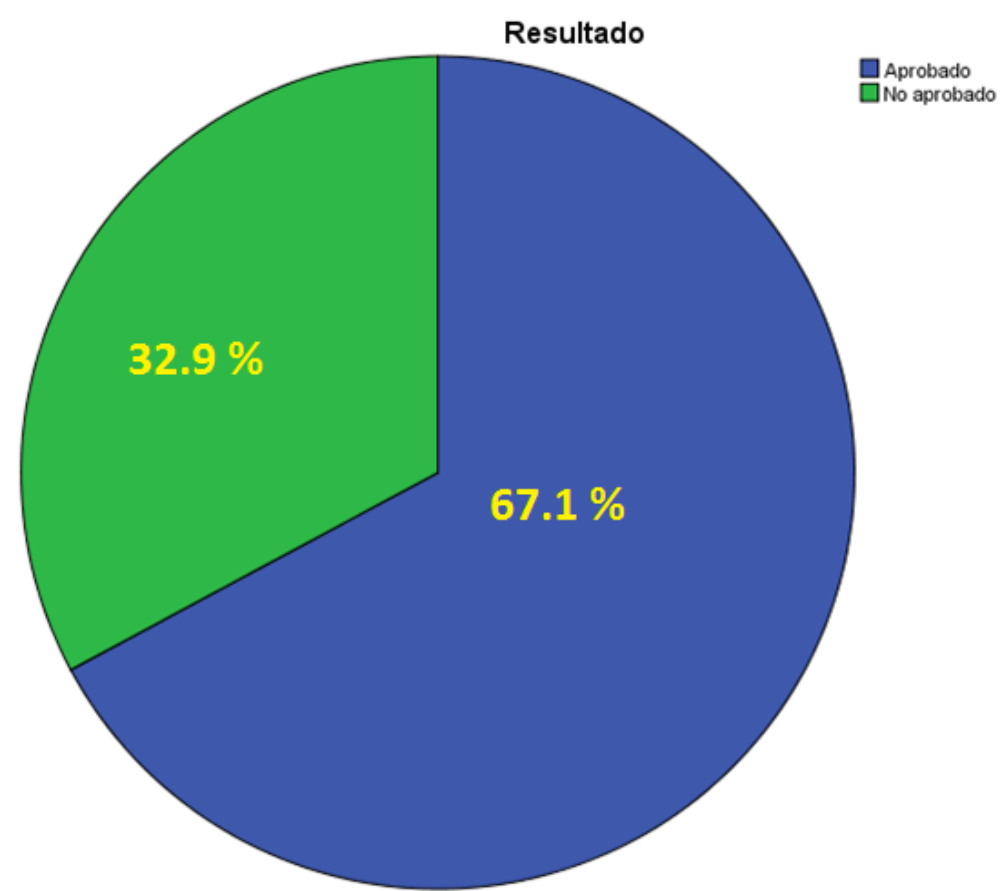

Figura 3. Porcentaje de Aprobación de los docentes de Soacha

\section{Conclusión}

A partir del análisis estadístico de los datos aplicando la prueba T-Student, se puede observar que hay evidencia para rechazar la hipótesis alterna, por tanto las medias son significativamente iguales, es decir no hay diferencia entre el resultado obtenido por hombres y mujeres en la Evaluación de Carácter Diagnóstico Formativa en el año 2016 por parte de los docentes de Soacha-Cundinamarca.

Las instituciones educativas con mejor promedio de aprobación fueron: Eugenio Díaz Castro, Buenos Aires, Cazucá, Julio Cesar Turbay y Manuela Beltrán. Y las de menor promedio de aprobación fueron: Compartir, Centro Educativo El Pasto, Eduardo Santos, Gabriel García Márquez, Ricaurte y la Despensa.

El porcentaje de aprobación de la ECDF por parte de los docentes de Soacha, hombres y mujeres fue del $67.1 \%$ y de no aprobación del $32.9 \%$, es un buen resultado tanto para reubicación salarial como para el ascenso de los docentes.

\section{Bibliografía}

Balestrini, M. (2006). Cómo se Elabora el Proyecto de Investigación. Venezuela: Servicio Editorial.

MEN (Ministerio de Educación Nacional) (2015). Evaluación Diagnóstica Formativa. Recuperado el 26 de febrero de 2017, de http://mineducacion.gov.co/1759/w3-article-244742.html 
MEN (Ministerio de Educación Nacional) (2015). Evaluación Diagnóstica Formativa. Recuperado el 26 de febrero de 2017, de http://www.mineducacion.gov.co/1759/w3-article-353929.html 